\title{
Characterization, physicochemical stability, and evaluation of in vitro digestibility of solid lipid microparticles produced with palm kernel oil and tristearin
}

Janaina Costa da SILVA ${ }^{1}$, Thais Ribeiro BORRIN ${ }^{1}$, Pâmela RUY ${ }^{1}$, Thais Carvalho BRITO ${ }^{1}$, Ana Cristina PINHEIRO², António Augusto VICENTE², Samantha Cristina de $\mathrm{PINHO}^{1 *}$

\begin{abstract}
Solid lipid particles have been investigated by food researchers due to their ability to enhance the incorporation and bioavailability of lipophilic bioactives in aqueous formulations. The objectives of this study were to evaluate the physicochemical stability and digestibility of lipid microparticles produced with tristearin and palm kernel oil. The motivation for conducting this study was the fact that mixing lipids can prevent the expulsion of the bioactive from the lipid core and enhance the digestibility of lipid structures. The lipid microparticles containing different palm kernel oil contents were stable after 60 days of storage according to the particle size and zeta potential data. Their calorimetric behavior indicated that they were composed of a very heterogeneous lipid matrix. Lipid microparticles were stable under various conditions of ionic strength, sugar concentration, temperature, and $\mathrm{pH}$. Digestibility assays indicated no differences in the release of free fatty acids, which was approximately $30 \%$ in all analises. The in vitro digestibility tests showed that the amount of palm kernel in the particles did not affect the percentage of lipolysis, probably due to the high amount of surfactants used and/or the solid state of the microparticles.
\end{abstract}

Keywords: lipid microparticles; palm kernel oil; dynamic in vitro simulated digestion; medium-chain triglycerides.

\section{Introduction}

The bioavailability of hydrophobic micronutrients can be enhanced by the presence of lipids, and such enhancement is mainly attributed to the lipid capacity to affect the physical and biochemical barrier functions of the gastrointestinal tract and to stimulate secretion of bile salts and endogenous biliary lipids (Porter et al., 2007). Therefore, it would be interesting to formulate food microencapsulation systems using lipid-based matrices, such as emulsions, liposomes, and lipid particles (Salvia-Trujillo et al., 2013; McClements, 2012; Weiss et al., 2008).

Solid lipid particles are produced by replacing the oily core of an oil-in-water emulsion with a solid lipid at room temperature (Salminen et al., 2014; Umeyor et al., 2012). Some advantages of using these particles to load hydrophobic ingredients are their biodegradability, full biocompatibility, and high capacity for incorporating lipophilic compounds. To avoid low encapsulation loads and decrease the risk of expulsion of the encapsulated bioactive due to a high degree of crystallinity of the lipid core, it is preferable to use naturally ocurring fats, which are mixtures of different types of triacylglycerols with different fatty acid lengths and degrees of unsaturation (Mehnert \& Mäder, 2001; Müller et al., 2000).

Among the most commonly fats used for food purposes is palm kernel oil (PKO), which is a mixture of high- and lowmelting triglycerides and lauric oil; it is extensively used both in food and oleochemical industries (Siew, 2001). In addition to having the capacity of structuring less ordered matrices, medium-chain triacylglycerides (MCT)-rich lipids may have the advantage of enhancing the bioavailability of encapsulated hydrophobic bioactives, and MCTs are hydrolysed five times faster and more completely than long-chain triacylglycerides in the small intestine (Martem et al., 2006). Moreover, MCTs are eliminated from the circulation twice as rapidly as LCTs, have a smaller impact on serum cholesterol levels, and are not stored in body tissues when consumed in normal amounts (Man \& Manaf, 2006). The benefits of using LCTs or MCTs (or mixtures of both types) in enhancing bioavailability of an oral bioactive is determined by their physicochemical properties and specific interactions with the encapsulating structures. In vitro lipid digestion models might provide useful information with respect to the design of a formulation (Dahan \& Hoffman, 2008).

The aims of the present study were to produce lipid microparticles with various amounts of long-chain (tristearin) and medium-chain (present in palm kernel oil) tricylglycerides, to evaluate their physicochemical stability during storage under different environmental conditions $(\mathrm{pH}$, temperature, ionic strength, and sugar concentration), and to assess their in vitro digestibility.

\section{Materials and methods}

\subsection{Materials}

Tristearin (TS), polysorbate 60 (PS60), and span 80 (SP80) were obtained from Sigma (St. Louis, USA); xanthan gum (XG, Grindsted Xanthan $80^{\circ}$ ) was donated by Danisco (Cotia, Brazil); and palm kernel oil (PKO) was donated by Agropalma (Belém, Brazil). For the simulated digestion juices, it was used lipase 
from porcine pancreas L3126 (type II), bile extract porcine B8631, pepsin and mucin; all of them were purchased from Sigma (St. Louis, USA). All other chemicals used in this study were reagent grade.

\subsection{Determination of the hydrophilic-lipophilic balance value (HLB) of lipid mixtures used to produce lipid microparticles}

The stability of lipid microparticles produced using HLB values in the range of 7.6 to 13.8 were tested. The aqueous phase consisted of water and a hydrophilic surfactant (PS60, HLB $=15.0$ ). The oil phase consisted of a mixture of tristearin, $\mathrm{PKO}$, and a hydrophobic surfactant (SP80, HLB = 4.3). The protocol used was the same as that used by Severino et al. (2011), and the analyses were conducted in triplicate.

\section{Production of solid lipid microparticles}

Lipid microparticles were produced by melting the lipid phase (TS and PKO) at $70{ }^{\circ} \mathrm{C}$ together with the hydrophobic surfactant (SP80) according to the formulations presented in Table 1.

The hot hydrophilic surfactant (PS60) solution $\left(70^{\circ} \mathrm{C}\right)$ was mixed with the melted lipid and stirred at 18,000 rpm for $5 \mathrm{~min}$. The emulsions were then magnetically stirred, and xanthan gum was added $(0.05 \% \mathrm{w} / \mathrm{w})$. Afterwards, the microparticle dispersions were cooled to $20^{\circ} \mathrm{C}$ in an ice bath. The samples, produced in triplicate, were stored under refrigeration $\left(7-10^{\circ} \mathrm{C}\right)$.

\subsection{Determination of average hydrodynamic diameter, size distribution, and zeta potential}

Average hydrodynamic diameters and size distributions of lipid microparticles were obtained by photon correlation spectroscopy (90Plus, Brookhaven Instruments Company, USA) at $25^{\circ} \mathrm{C}$. The zeta potential in purified water was obtained using a ZetaPlus analyzer (Brookhaven Instruments Company, USA).

\subsection{Differential scanning calorimetry (DSC)}

Thermal analyses of lipid microparticles by DSC were carried out using a ramp of $10{ }^{\circ} \mathrm{C} / \mathrm{min}$ in the range of 0 to $100{ }^{\circ} \mathrm{C}$ using a TA5000 (TA Instruments, USA). The reference used was an empty aluminum pan. The calorimetric runs were carried out in duplicate.

\subsection{Wide-angle X-ray diffraction (WAXD)}

The wide angle $\mathrm{X}$-ray diffraction analyses were conducted in a Philips PW1710 (Phillips, The Netherlands) equipped with a copper anode that delivered an X-ray wavelength of $\lambda=1.5418 \AA$ Á. The measurements were obtained at $10^{\circ} \mathrm{C}$ (storage temperature) in the range of $2 \theta$ from 0 to $40^{\circ}$ using $0.02^{\circ}$ steps.

\subsection{Physicochemical stability of lipid microparticles under different stress conditions}

Physicochemical stability of lipid microparticles was assessed by measuring phase separation (\% of the total height of the liquid column inside a test tube).

Influence of $\mathrm{pH}$ : the $\mathrm{pH}$ of microparticle dispersions was adjusted to two different values (3.0 and 8.0); the dispersions were then poured into a test tube that was capped and observed for $24 \mathrm{~h}$ at $25^{\circ} \mathrm{C}$.

Heat treatments: the samples were submitted to 45 and $75^{\circ} \mathrm{C}$ by placing the test tubes containing the dispersions in a water bath at these temperatures.

Influence of salt concentration: different amounts of sodium chloride were added to the particle dispersions resulting in salt concentrations between 0.025 and $1.0 \mathrm{~mol} / \mathrm{L}$. Emulsions were vigorously shaken and stored for $24 \mathrm{~h}$ at $25{ }^{\circ} \mathrm{C}$ before visual analysis of phase separation and particle size distribution.

Influence of sugar concentration: different amounts of sucrose were added to particle dispersions resulting in sucrose concentrations ranging from 1.5 to $15 \%$ on a weight basis. Emulsions were vigorously shaken and stored for $24 \mathrm{~h}$ at $25^{\circ} \mathrm{C}$ before visual analysis of phase separation and particle size distribution. All analyses were conducted in triplicate.

\subsection{Evaluation of in vitro digestibility}

A dynamic in vitro system that simulated the digestive process was used to evaluate the digestibility of lipid microparticles of palm kernel oil and tristearin. Gastric and duodenal steps were simulated using the fluids described by Hur et al. (2009). A total of $20 \mathrm{~mL}$ of each of the lipid microparticle dispersions were placed in the gastric compartment in which a simulated gastric fluid $(12 \mathrm{~mL})$ was injected at the rate of $0.10 \mathrm{~mL} / \mathrm{min}$ for 2 hours. The gastric mixture was then transferred to a duodenal compartment in which the simulated duodenal and biliary juices were injected at $0.10 \mathrm{~mL} / \mathrm{min}$ and $0.05 \mathrm{~mL} / \mathrm{min}$, respectively, for 2 hours by means of syringe pumps. The apparatus mantained the $\mathrm{pH}$ in the gastric compartment at 2.0 and at 6.5 in the duodenal compartment by injecting acid or alkaline solutions when changes in the $\mathrm{pH}$ were detected. The temperature was kept at $37^{\circ} \mathrm{C}$ during the whole experiment. Digested particles were analysed for particle size distribution, zeta potential, and amount of free fatty acids or FFA (\% of released fatty acids). The FFA amount was determined (in triplicate) by titration with $0.01 \mathrm{~mol} / \mathrm{L} \mathrm{NaOH}$ (Bonnaire et al., 2008). The digestibility assays were conducted in duplicate.

Table 1. Formulations of lipid microparticles produced with tristearin and palm kernel oil.

\begin{tabular}{lll}
\hline Particle & \multicolumn{1}{c}{ Lipid phase } & \multicolumn{1}{c}{ Surfactants } \\
\hline PKO-90 & $2.8 \% \mathrm{TS}+1.2 \% \mathrm{PKO}$ & $1.0 \% \mathrm{SP} 80+3.0 \% \mathrm{PS} 60$ \\
PKO-70 & $2.0 \% \mathrm{TS}+2.0 \% \mathrm{PKO}$ & $2.8 \% \mathrm{SP} 80+1.2 \% \mathrm{PS} 60$ \\
PKO-50 & $1.2 \% \mathrm{TS}+2.8 \% \mathrm{PKO}$ & $2.8 \% \mathrm{SP} 80+1.2 \% \mathrm{PS} 60$ \\
PKO-30 & $0.4 \% \mathrm{TS}+3.6 \% \mathrm{PKO}$ & $2.8 \% \mathrm{SP} 80+1.2 \% \mathrm{PS} 60$ \\
\hline
\end{tabular}




\section{Results and discussion}

\subsection{Characterization and shelf life of lipid microparticles containing palm kernel oil}

The most suitable HLB values or combinations of surfactants for each particle formulation that resulted in the most stable dispersions were 12.3 for PKO-90 and 7.5 for PKO-70, PKO-50, and PKO-30. Therefore, lipid microparticles were produced according to the values of HLB obtained in such experiments. Figure 1 shows particle size distribution for each type of dispersion produced.

The high stability of lipid microparticles can be explained by the fact that all dispersion components were rich in $\mathrm{C} 18$ chains. The length of core acyl chains determines their ability to interpenetrate the surface monolayer (Tanaka et al., 2003). Furthermore, polysorbate molecules adsorbing to the hydrophobic surfaces form a stable and robust monolayer with a high capacity to resist collisions (Graca et al., 2007; Stalidis et al., 1990).

Their average hydrodynamic diameter and size distribution were determined during the 60 days of storage and are shown in Figure 1. The mean hydrodynamic diameter remained stable in all microparticles produced, which is clear from the size
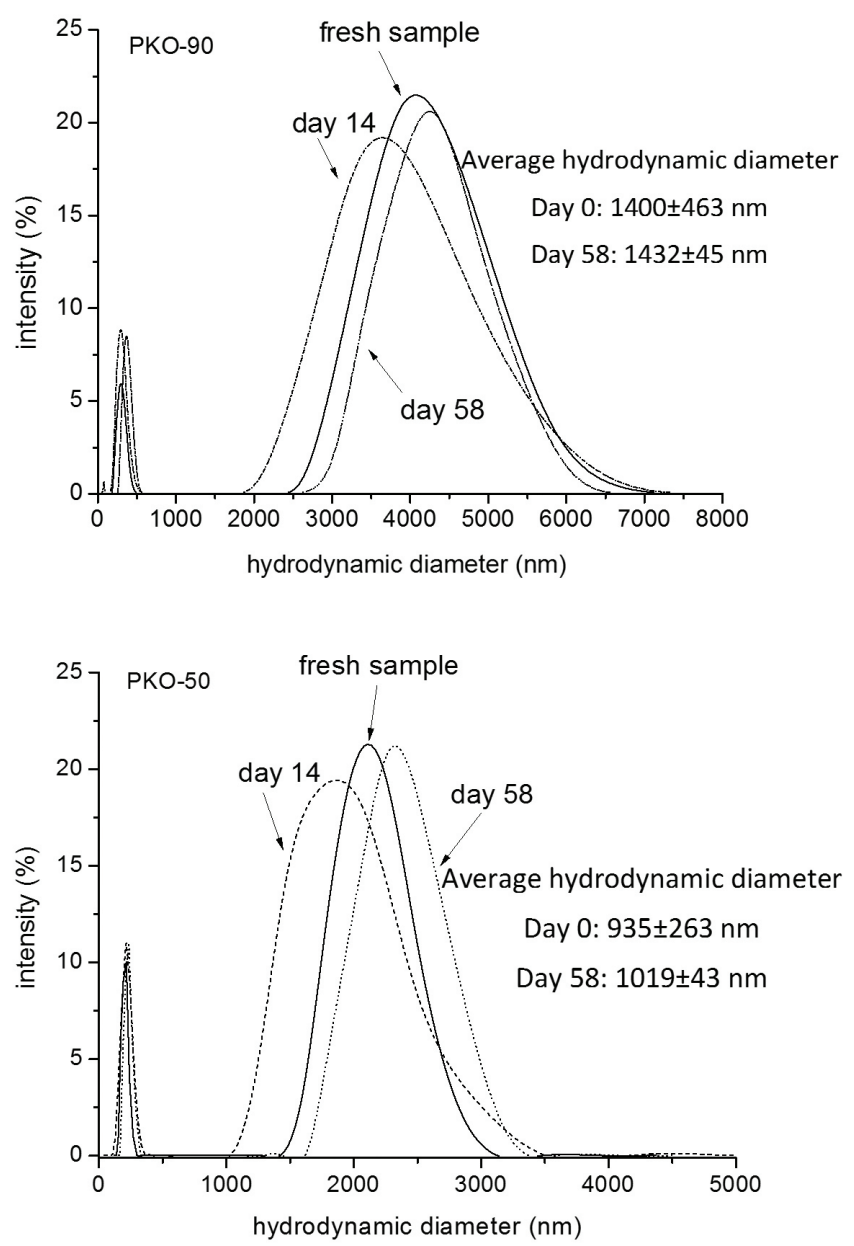

distribution curves shown in Figure 1. The zeta potential of all fresh formulations was negative, in the range from $-23.2 \pm 0.22$ to $-31.0 \pm 4.05 \mathrm{mV}$, corroborating the stability of the dispersions indicated by the size distribution curves.

The thermal behavior of lipid microparticles is shown in Figure 2. Thermal data reflect the heterogeneous composition of lipid microparticles. All dispersions had a minimum of two endothermic phase transitions: low melting temperature peak in the range from 20 to $32^{\circ} \mathrm{C}$, which was associated with the structures formed by MCTs, and a higher melting temperature peak at $52-55{ }^{\circ} \mathrm{C}$, which was associated with the structures formed by LCTs. The detected melting events and the occurrence of several peaks can also be attributed to a remarkable particle size effect (Bunjes \& Unruh, 2007).

The crystalline state of lipid microparticles was assessed by WAXD, and the resulting diffractograms are shown in Figure 3a. For comparison purposes, only the diffractograms of pure lipids are shown in Figure 3b. From these results, it is clear that all dispersions were completely amorphous at the tested temperature $\left(10^{\circ} \mathrm{C}\right)$. Such characteristic is extremely important because a low degree of crystallinity indicates a disorganized structure that is more suitable to accommodate encapsulated molecules (Attama et al., 2006; Attama \& MüllerGoymann, 2007).
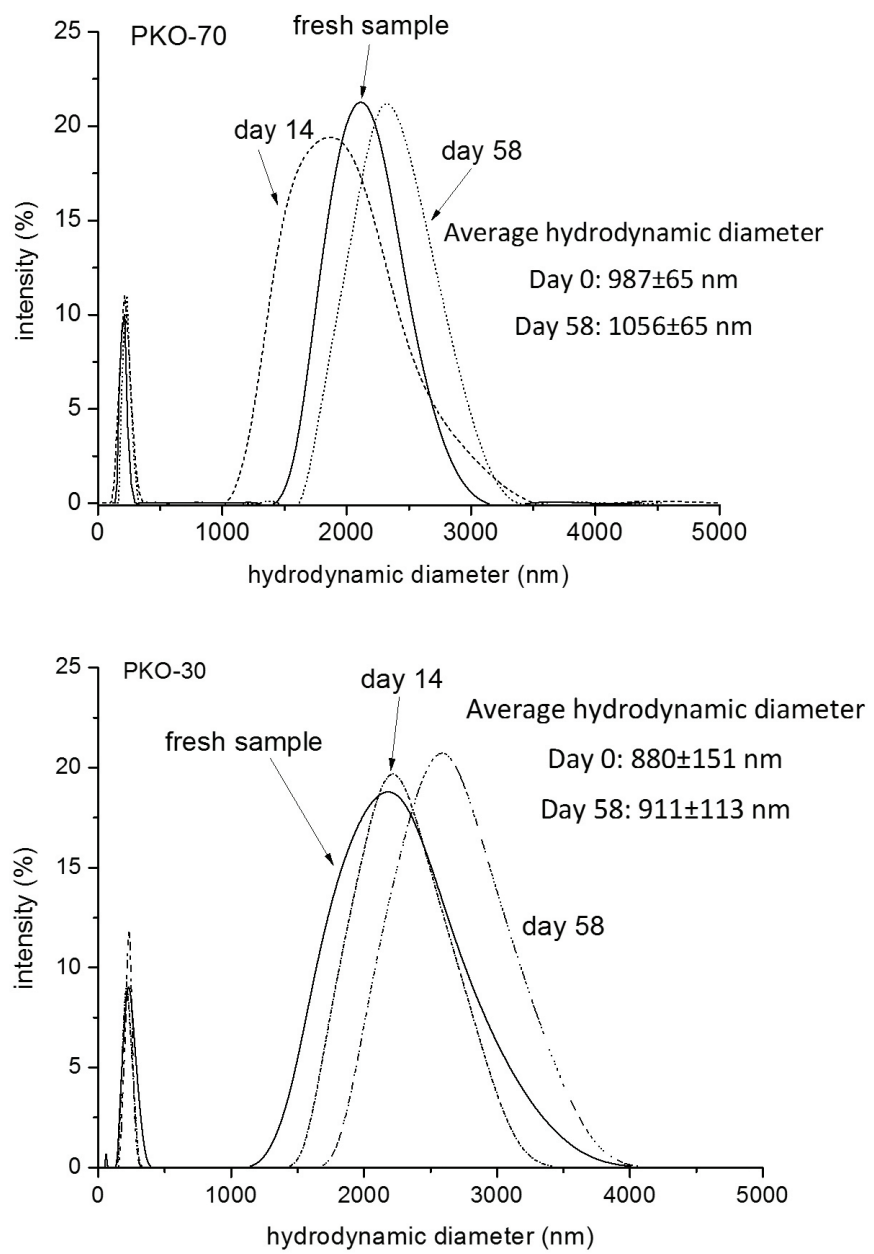

Figure 1. Particle size distribution of lipid microparticles produced with tristearin and palm kernel oil during storage. 


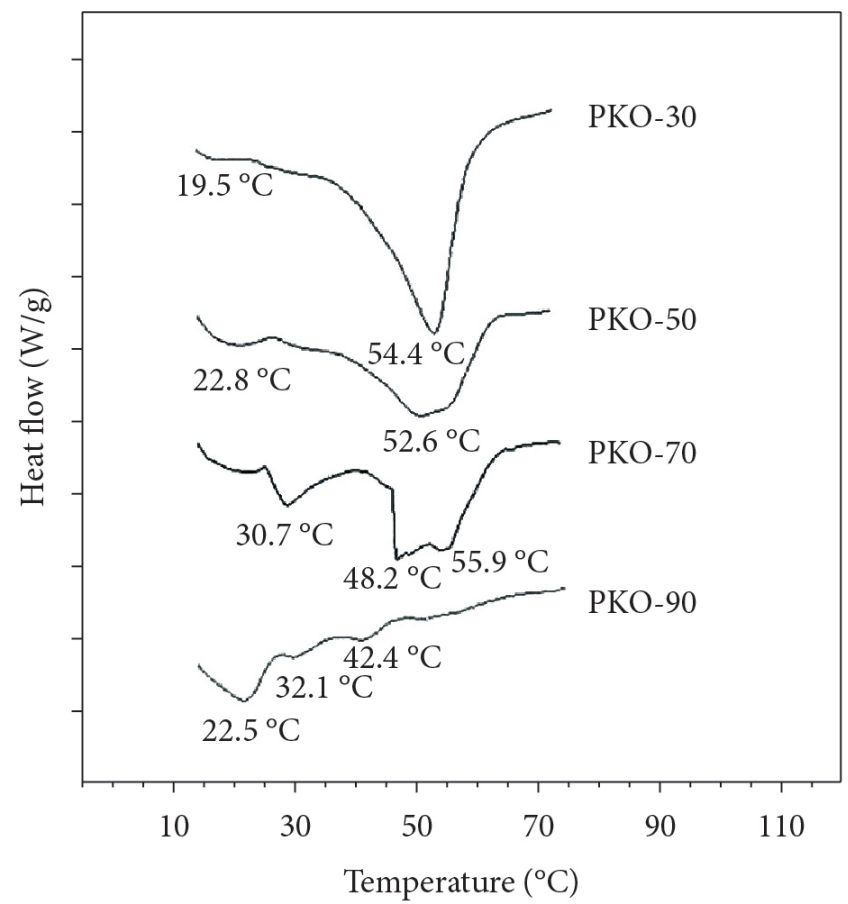

Figure 2. Thermograms of lipid microparticles produced with tristearin and palm kernel oil obtained by DSC.

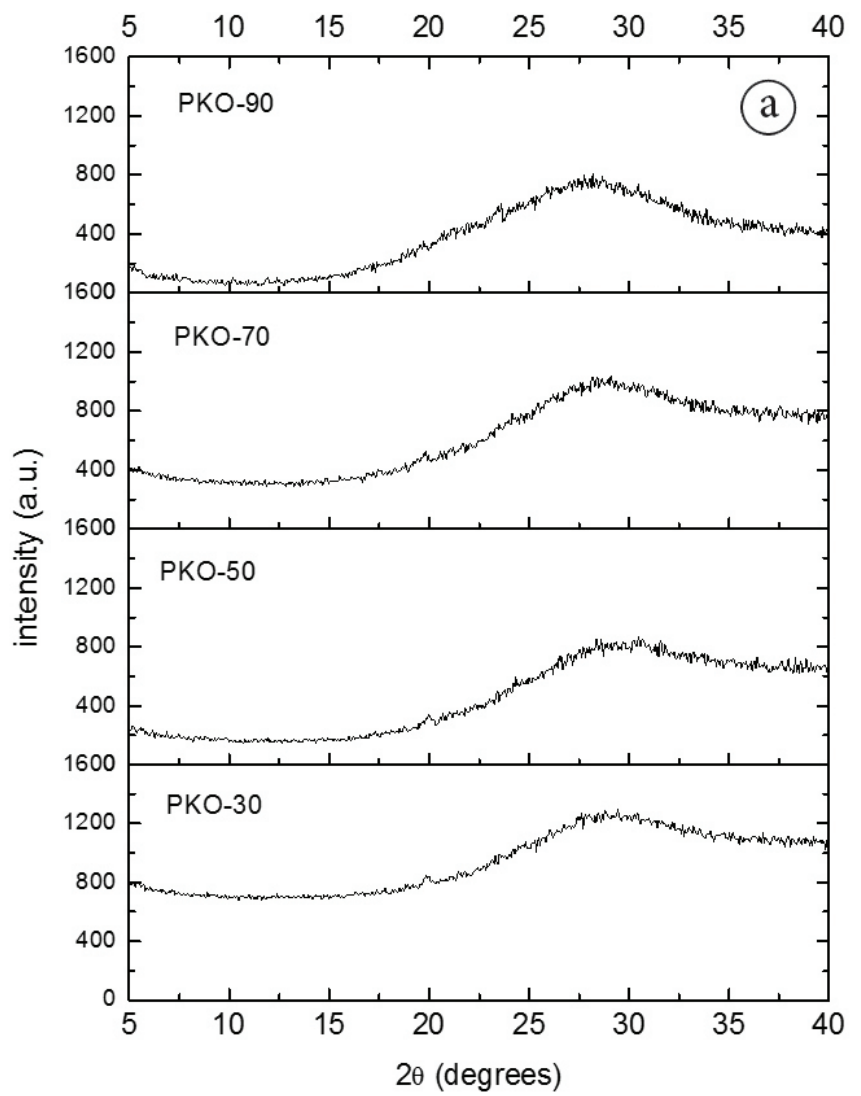

\subsection{Evaluation of the physicochemical stability of lipid microparticles under different stress conditions}

Figure 4 shows results of the destabilization resistance of lipid microparticles under different conditions of $\mathrm{pH}$, temperature, ionic strength, and sucrose concentration. With respect to temperature, all lipid microparticles (with the exception of PKO-30 particles) were extremely susceptible to destabilization at $45^{\circ} \mathrm{C}$. Considerable aggregation occurred at this temperature, most likely because PKO-50, PKO-70 and PKO-30 particles were partially crystalline, as shown by DSC results in Figure 2, which may have led to partial coalescence. The PKO-30 formulation was more resistant to destabilization at such temperature because its major core lipid fraction was still solid, minimizing partial coalescence effects.

Apparently, xanthan gum circumvented the effects caused by the presence of sucrose molecules. Such disaccharide molecules are known to destabilize colloidal particles due to depletion flocculation caused by the balance change in the intermolecular forces acting at the oil-water and fat crystal-water interfaces (Rodriguez-Spong et al., 2004). However, such a phenomenon did not occur at a great extent in our systems since the phase separation was practically absent in the lipid microparticles mixed with the different concentrations of sucrose.

PKO-90 formulation was the most resistant to higher salt concentrations. This is likely due to the different interface

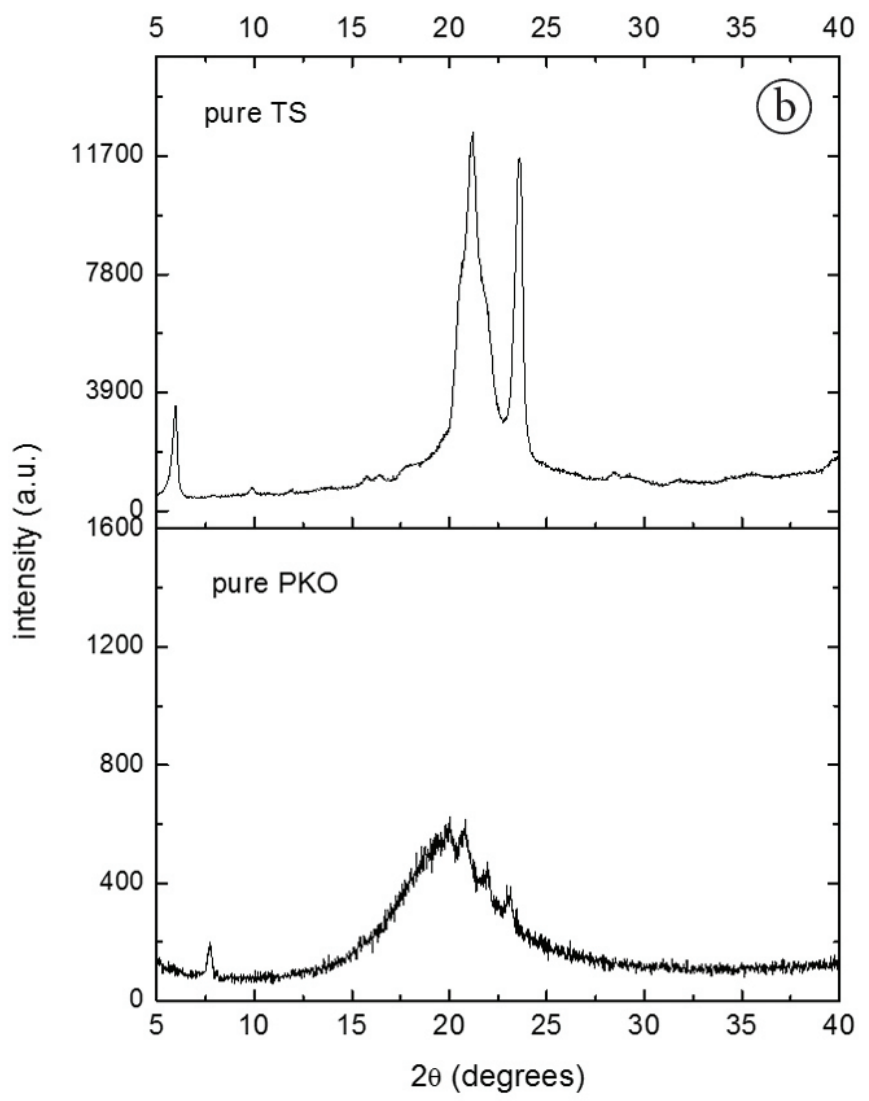

Figure 3. WAXD data: (a) Lipid microparticles produced with different amounts of palm kernel oil; (b) bulk lipids. 


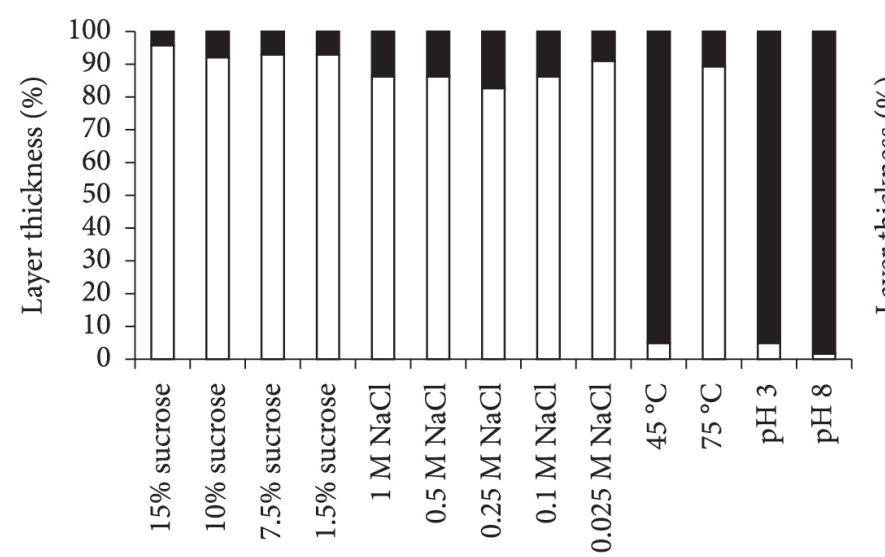

PKO-90

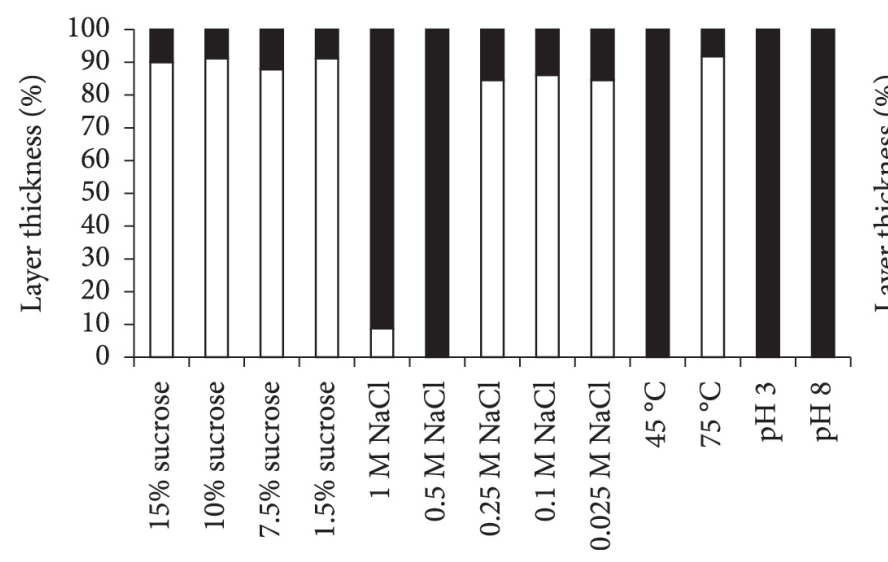

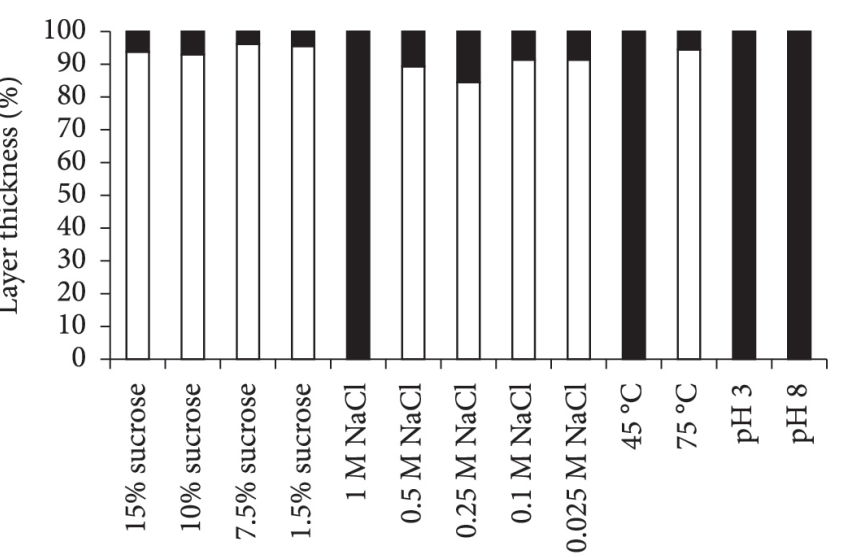

PKO-70

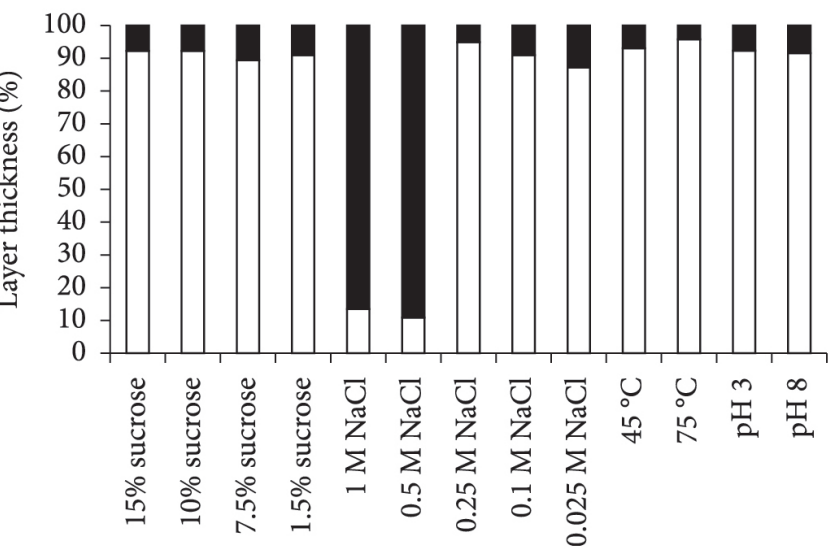

Figure 4. Stability of lipid microparticles (in terms of the \% thickness of the emulsion layer) composed of tristearin and palm kernel oil under different environental conditions ( $\square$ emulsion phase; $\mathbf{c}$ cream phase).

composition; the interface layer of lipid microparticles containing $90 \%$ of PKO was composed of $75 \%$ of PS60 and $25 \%$ of SP 80 , whereas the other formulations contained $30 \%$ of PS60 and 70\% of SP80. A higher percentage of PS60 resulted in a thicker stabilization layer around the particles due to the higher number of polyoxyethylene chains, which may have helped reduce creaming rate.

With the exception of PKO-30, $\mathrm{pH}$ seemed to be a strong factor of instability in the produced dispersions. Changes in $\mathrm{pH}$ strongly affect interface properties and, consequently, they may lead to colloidal destabilization processes such as flocculation and creaming. The more homogeneous lipid matrix in PKO30 formulations, however, could have been more effective in preventing a severe movimentation of surfactant chains during collisions, thus making the destabilization processes (flocculation and posterior creaming) less prone to occur in such cases.

\subsection{Evaluation of in vitro digestibility assays}

Lipid microparticle dispersions underwent changes in their microstructure after being submitted to the simulated digestive process. After the gastric step, particle size distribution was not strongly altered (data not shown). Such behavior was expected because the dispersions were exposed to drastic $\mathrm{pH}$ changes, high ionic strengths, and the presence of $\mathrm{Ca}^{2+}$ ions, which led to changes in the characteristics of their interface layer ( $\mathrm{Li}$ et al., 2011). Such interface changes, which were due to interactions with digestion fluids' components, can also be demonstrated by the alterations in zeta potential values, as shown in Figure 5a. Zeta potential values became less negative after the gastric step because surfactant molecules were possibly substituted for the surfactant species present in the gastric juice and/or for charged species (Hur et al., 2009). On the other hand, at the end of the duodenal step, zeta potential became more negative most likely due to the adsorption of bile salts and lipase/colipase complexes to the surface of lipid particles (Hur et al., 2009). As for FFA formation, there was almost no difference in the amount of fatty acids released between the particle formulations (approximately $30 \%$ ). Low molecular weight surfactants may impair the access of lipolytic enzymes to the surface of lipid particles, as they interact weakly with proteins (Reis et al., 2008; MacGregor et al., 1997). In the case of PS60, their polyethoxylated groups may also cause steric hindrance (Torcello-Goméz et al., 2011). The concentration used to produce the lipid microparticles (4\%), which can be considered high in comparison to those of other studies on in vitro digestibility of emulsions stabilized with polysorbates (Hur et al., 2009; Li et al., 2011), may also have influenced in the lipolysis rate observed. The stabilizing interface of the microparticles was highly stable, as demonstrated by 

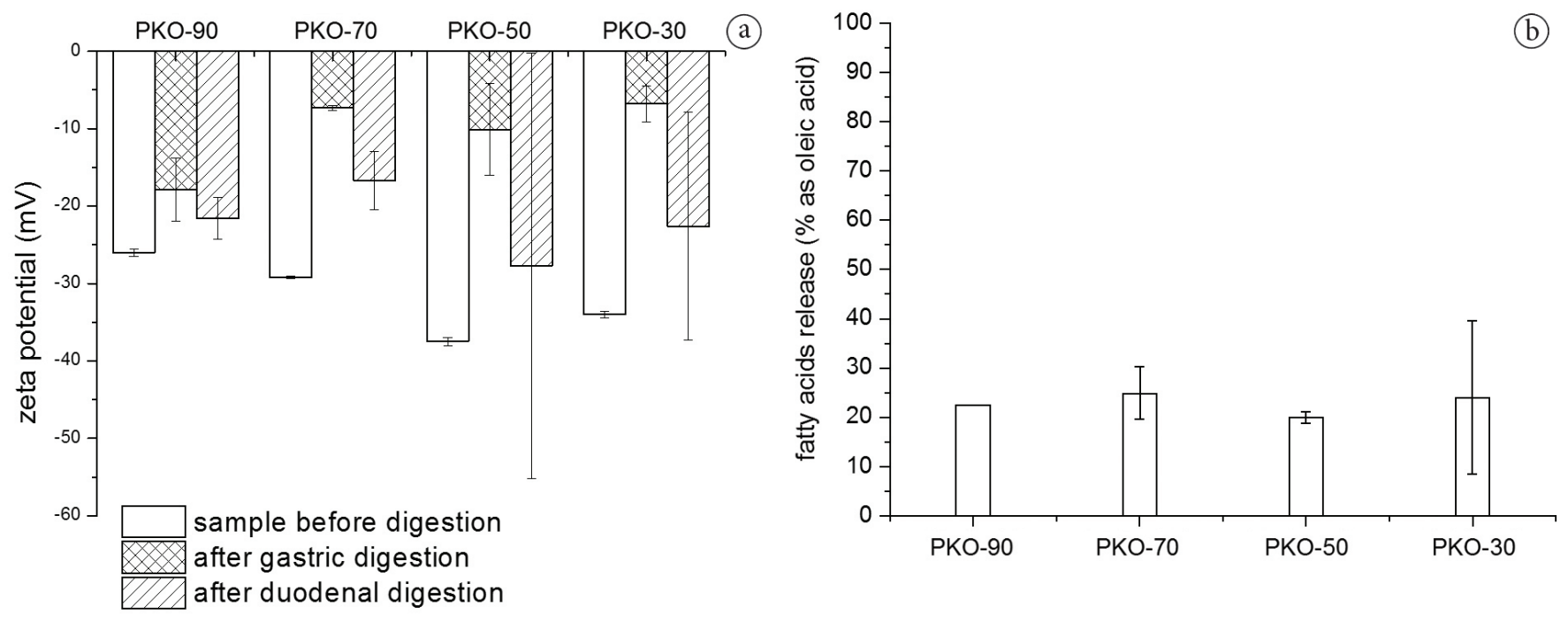

Figure 5. Results of the dynamic in vitro simulated digestion: (a) zeta potential values after gastric and duodenal simulated digestion steps; (b) released fatty acids (\% as oleic acid) after the duodenal simulated digestion step.

the results of shelf life in Figure 1; this fact indicated that the interface was probably formed by tightly packed surfactant molecules. Such a packed and stable interface may have reduced the access of the lipase molecules to the triglycerides in the particles' core.

In addition, apparently, the amount of MCT did not influence the hydrolysis percentage at the end of the simulated digestive process, as initially supposed. Such a fact is also probably related to the fact the particles' core were, at least, partially solid at $37^{\circ} \mathrm{C}$. The physical state influences the rate and extent of lipid digestion in solid lipid particles since it affects the accessibility of lipase to the ester bond in the tricylglyceride molecules (McClements \& Li, 2010). In our case, the particle formulations contained different amounts of palm kernel oil, but, in all cases, as it was included in a core at least partially solid, such a fact was probably the major influence on the fatty acid release from the microparticles. In the studies of in vitro digestibility of lipid colloidal systems containing MCTs, they are emulsions, and therefore they have a liquid core (Bonnaire et al., 2008). It is not possible, therefore, to compare the results of fatty acid release of our MCT solid lipid particles system directly with MCT emulsions since the lipid state is different, and, most probably, it is a factor of high importance in the final result of the in vitro digestibility tests.

\section{Conclusions}

All lipid microparticles produced were quite stable for an extended shelf life, and the mixture of two completely different lipid raw materials resulted in a highly heterogeneous core. The microparticles demonstrated a high potential to be used in food systems as they had a high level of stability under typical sugar concentrations and ionic strengths. The low stability at low $\mathrm{pH}$ may not pose a problem if the particles are entrapped in a much more complex medium than a water medium, which could retard the destabilization processes. Digestibility assays demonstrated that microparticle dispersions were digestible and the release of free fatty acids did not increase with higher MCT amounts. Such a result may be due to the lipid state since lipid particles were prone to partial coalescence, which led to the formation of aggregates that may have impaired the access of lipase to the lipid molecules. The solid lipid may also have increased the difficulty of lipase to access the triglyceride ester bond to be hydrolysed. The absence of a very fast digestive process indicates that lipid microparticles can be engineered to serve as efficient controlled release systems. More studies, however, are necessary to investigate the influence of the concentration of surfactants present in the stabilizing layer in the rate of lipid digestion.

\section{Acknowledgements}

The authors are grateful to the FAPESP and CNPq for the scholarships granted (J.C.S., FAPESP fellowships 2010/13229-8 and 2012/02316-2, and T.R.B, FAPESP fellowship 2010/15031-0) and to Agropalma S/A for their generous palm kernel oil donation. Author Ana C. Pinheiro gratefully acknowledges the fellowship (SFRH/BD/48120/2008) granted by the Fundação para a Ciência e Tecnologia (FCT, Portugal).

\section{References}

Attama, A. A., \& Müller-Goymann, C. C. (2007). Investigation of surface-modified solid lipid nanocontainers formulated with a heterolipid-templated homolipid. International Journal of Pharmaceutics, 334(1-2), 179-189. PMid:17140752. http://dx.doi. org/10.1016/j.ijpharm.2006.10.032

Attama, A. A., Schicke, B. C., \& Müller-Goymann, C. C. (2006). Further characterization of theobroma oil-beeswax admixtures as lipid matrices for improved drug delivery systems. European Journal of Pharmaceutics and Biopharmaceutics, 64(3), 294-306. PMid:16949805. http://dx.doi.org/10.1016/j.ejpb.2006.06.010 
Bonnaire, L. S., Helgason, T., Decker, E. A., Weiss, J., \& McClements, D. J. (2008). Influence of lipid physical state on the in vitro digestibility of emulsified lipids. Journal of Agricultural and Food Chemistry, 56(10), 3791-3797. PMid:18433107. http://dx.doi.org/10.1021/ jf800159e

Bunjes, H., \& Unruh, T. (2007). Characterization of lipid nanoparticles by differential scanning calorimetry, X-ray and neutron scattering. Advanced Drug Delivery Reviews, 59(6), 379-402. PMid:17658653. http://dx.doi.org/10.1016/j.addr.2007.04.013

Dahan, A., \& Hoffman, A. (2008). Rationalizing the selection of oral lipid based drug delivery systems by na in vitro dynamic lipolysis model for improved oral bioavailability of poorly water soluble drugs. Journal of Controlled Release, 129(1), 1-10. PMid:18499294. http://dx.doi.org/10.1016/j.jconrel.2008.03.021

Graca, M., Bongaerts, J. H. H., Stokes, J. R., \& Granick, S. (2007). Friction and adsorption of aqueous polyoxyethylene (Tween) surfactants at hydrophobic surfaces. Journal of Colloid and Interface Science, 315(2), 662-670. PMid:17706238. http://dx.doi. org/10.1016/j.jcis.2007.06.057

Hur, S. J., Lim, B. O., Decker, E. A., \& McClements, D. J. (2009). Influence of initial emulsifier type on microstructural changes occurring in emulsified lipids during in vitro digestion. Food Chemistry, 114(1), 253-262. http://dx.doi.org/10.1016/j.foodchem.2008.09.069

Li, Y., Hu, M., \& McClements, D. J. (2011). Factors affecting lipase digestibility of emulsified lipids using an in vitro digestion model: proposal for a standardised $\mathrm{pH}$-stat method. Food Chemistry, 126(2), 498-505. http://dx.doi.org/10.1016/j.foodchem.2010.11.027

MacGregor, K. J., Embleton, J. K., Lacy, J. E., Perry, E. A., Solomon, L. J., Seager, H., \& Pouton, C. W. (1997). Influence of lipolysis on drug absorption from the gastro-intestinal tract. Advanced Drug Delivery Reviews, 25(1), 33-46. http://dx.doi.org/10.1016/S0169409X(96)00489-9

Man, Y. B. C., \& Manaf, M. A. (2006). Medium-chain triacylglycerols. In F. Shaidi (Ed.), Nutraceutical and specialty lipids and their coproducts. Boca Raton: Taylor and Francis. p. 27-56.

Marten, B., Pfeuffer, M., \& Schrezenmeier, J. (2006) Medium-chain triglycerides. International Dairy Journal, 16(11), 1374-1382. http:// dx.doi.org/10.1016/j.idairyj.2006.06.015

McClements, D. J. (2012). Crystals and crystallization in oil-in-water emulsions: implications for emulsion-based delivery systems. Advances in Colloid and Interface Science, 174, 1-30. PMid:22475330. http://dx.doi.org/10.1016/j.cis.2012.03.002

McClements, D. J., \& Li, Y. (2010). Structured emulsion-based delivery systems: controlling the digestion and release of lipophilic food components. Advances in Colloid and Interface Science, 159(2), 213228. PMid:20638649. http://dx.doi.org/10.1016/j.cis.2010.06.010

Mehnert, W., \& Mäder, M. (2001). Solid lipid nanoparticles: production, characterization and applications, Advanced Drug Delivery Reviews, 47(2-3), 165-169. http://dx.doi.org/10.1016/ S0169-409X(01)00105-3

Müller, R. H., Mäder, K., \& Gohla, S. (2000). Solid Lipid Nanoparticles (SLN) for controlled drug delivery: a review of the state of the art. European Journal of Pharmaceutics and Biopharmaceutics, 50(1), 161-177. http://dx.doi.org/10.1016/S0939-6411(00)00087-4

Porter, C. J. H., Trevaskis, N. L., \& Charman, W. N. (2007). Lipids and lipid-based formulations: optimizing the oral delivery of lipophilic drugs. Nature Reviews: Drug Discovery, 6, 231-248. PMid:17330072. http://dx.doi.org/10.1038/nrd2197

Reis, P. M., Raab, T. W., Chuat, J. Y., Leser, M. E., Miller, R., Watzke, H. J., \& Holmberg, K. (2008). Influence of surfactants on lipase fat digestion in a model gastro-intestinal system. Food Biophysics, 3(4) 370-381. PMid:20401181 PMCid:PMC2854607. http://dx.doi. org/10.1007/s11483-008-9091-6

Rodriguez-Spong, B., Price, C. P., Jayasankar, A., Matzger, A. J., \& Rodriguez-Hornedo, N. (2004). General perspectives of pharmaceutical solid polymorphism: a supramolecular perspective. Advanced Drug Delivery Reviews, 56(3), 241-274. PMid:14962581. http://dx.doi.org/10.1016/j.addr.2003.10.005

Salminen, H., Helgason, T., Aulbacha, S., Kristinsson, B., Kristbergsson, K., \& Weiss, J. (2014). Influence of co-surfactants on crystallization and stability of solid lipid nanoparticles. Journal of Colloid and Interface Science, 426, 256-263. PMid:24863791. http://dx.doi. org/10.1016/j.jcis.2014.04.009

Salvia-Trujillo, L., Qian, C., Martin-Belloso, O., \& McClements, D. J. (2013). Influence of particle size on lipid digestion and $\beta$-carotene bioaccessibility in emulsions and nanoemulsions. Food Chemistry, 141(2), 1472-1480. PMid:23790941. http://dx.doi.org/10.1016/j. foodchem.2013.03.050

Severino, P., Pinho, S. C., Souto, E. B., \& Santana, M. H. A. (2011). Polymorphism, crystallinity and hydrophilic-hydrophobic balance of stearic acid and stearic acid-capric/caprylic triglyceride matrices for production of stable nanoparticles. Colloids and Surfaces B: Biointerfaces, 86(1), 125-130. PMid:21543196. http://dx.doi. org/10.1016/j.colsurfb.2011.03.029

Siew, W. L. (2001). Crystallisation and melting behaviour of palm kernel oil and related products by differential scanning calorimetry. European Journal Lipid Science Technology, 103(11), 729-743. http://dx.doi.org/10.1002/1438-9312(200111)103:11<729::AIDEJLT729>3.0.CO;2-L

Stalidis, G., Avranas, A., \& Jannakoudakis, D. (1990). Interfacial properties and stability of oil-in-water emulsions stabilized with binary mixtures of surfactants. Journal of Colloid and Interface Science, 135(2), 313-324. http://dx.doi.org/10.1016/00219797(90)90002-6

Tanaka, M., Saito, H., Arimoto, I., Nakano, M., \& Handa, T. (2003). Evidence for interpenetration of core triglycerides into surface phospholipid monolayers in lipid emulsions. Langmuir, 19(13), 5192-5196. http://dx.doi.org/10.1021/la026897q

Torcello-Gomez, A., Maldonado-Valderrama, J., Vicente, J., CabrerizoVilchez, M. A., Gálvez-Ruiz, M. J., \& Mártin-Rodriguez, A. (2011). Investigating the effect of surfactants on lipase interfacial behavior in the presence of bile salts. Food Hydrocolloids, 25(4), 809-816. http://dx.doi.org/10.1016/j.foodhyd.2010.09.007

Umeyor, E. C., Kenechukwu, F. C., Ogbonna, J. D., Chime, A. S., \& Attama, A. A. (2012). Preparation of novel solid lipid microparticles loaded with gentamicin and its evaluation in vitro and in vivo. Journal of Microencapsulation, 29(3) 296-307. PMid:22283701. http://dx.doi.org/10.3109/02652048.2011.651495

Weiss, J., Decker, E. A., McClements, D. J., Kristbergsson, K., Helgason, T., \& Awad, T. (2008). Solid lipid nanoparticles as delivery systems for bioactive food components. Food Biophysics, 3(2), 146-154. http://dx.doi.org/10.1007/s11483-008-9065-8 